\title{
BMR
}

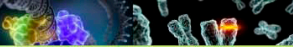

\section{Genetic variability of CYP3A4 in a heterogeneous Brazilian population from Maranhão}

\author{
S.C. Moutinho Monteiro ${ }^{1}$, I.H. de Sousa ${ }^{1}$, I.K. Pereira Belfort ${ }^{1}$, \\ J.D. Nunes ${ }^{1}$, B.A. Sousa Penha ${ }^{1}$, M. dos Santos ${ }^{2}$, I. Drumond Louro ${ }^{3}$ \\ and I.D.C. Guerreiro da Silva ${ }^{4}$ \\ 1Programa de Pós-Graduação em Saúde do Adulto e da Criança, \\ Universidade Federal do Maranhão, São Luís, MA, Brasil \\ ${ }^{2}$ Departamento de Medicina, \\ Universidade Federal do Rio Grande do Norte, Campus Caicó, \\ Caicó, RN, Brasil \\ ${ }^{3}$ Programa de Pós-Graduação em Biotecnologia, \\ Universidade Federal do Espírito Santo, Vitória, ES, Brasil \\ ${ }^{4}$ Laboratório de Ginecologia Molecular, \\ Departamento de Ginecologia, Universidade Federal de São Paulo, \\ São Paulo, SP, Brasil \\ Corresponding author: S.C. Moutinho Monteiro \\ E-mail: sallycris@yahoo.com
}

Genet. Mol. Res. 15 (1): gmr.15017275

Received July 22, 2015

Accepted October 28, 2015

Published February 19, 2016

DOI http://dx.doi.org/10.4238/gmr.15017275

\begin{abstract}
Inter-individual variability in drug metabolism may result in adverse drug responses. Pharmacogenetic studies have shown that polymorphisms in drug metabolizing enzymes may contribute to this variability. Among these enzymes, CYP3A4 is responsible for metabolizing over $50 \%$ of the clinically used drugs. The Brazilian population is composed of people with Native American, European, and African ancestries, and is therefore considered as one of the most intermixed populations in the world. A thorough knowledge of the genetic frequencies of CYP3A4
\end{abstract}


allelic variants is useful for the establishment of better pharmacological therapies; therefore, the aim of this study was to describe the polymorphic frequencies for CYP3A4-392A $>G$ (rs2740574) in a sample population from Maranhão, Brazil. Our results showed that $75.1,21.9$, and $3.0 \%$ of the individuals expressed the -392AA, -392AG, and -392GG genotypes, respectively. The $-392 \mathrm{~A}$ and $-392 \mathrm{G}$ alleles were observed in 86.1 and $13.9 \%$ of the population, respectively. Our results reiterate the need for a better understanding of the variations in the genotype and allele frequencies of CYP3A4 -392A $>\mathrm{G}$ polymorphisms in various Brazilian regions, in order to elucidate the variability in drug response.

Key words: CYP3A4*1B; Polymorphism; Genetic variability; Drug metabolism; Pharmacogenetics

\section{INTRODUCTION}

The new genetic pool contributed to a high degree of variability, directly affecting most of the genetic polymorphic traits, such as the genes of the P450 cytochrome superfamily. The P450 cytochromes are heme proteins that catalyze the metabolism of a large number of xenobiotics and endobiotics, which are largely responsible for the clearance of therapeutic drugs (Deenen et al., 2011). Among these, special importance has been attributed to the CYP3A4 gene by previous researchers.

CYP3A4 is highly expressed in the liver and small intestine (Shimada et al., 1994), and metabolizes $>50 \%$ of the clinically administered drugs (Guengerich, 1999; Rodriguez-Antona et al., 2005). The enzyme activity of CYP3A4 has a wide subject-specific range; this activity can be affected by non-genetic factors, such as the age, endogenous hormone levels, health status, and environmental stimuli, in addition to genetic polymorphism (Ozdemir et al., 2000).

To date, approximately 40 allelic variants have been described for CYP3A4, some of which are responsible for a reduction in human cytochrome $\mathrm{P} 450$ activity. In addition, a common polymorphism located in the promoter region of the gene (CYP3A4 -392A $>\mathrm{G}$ rs2740574; the $-392 \mathrm{G}$ allele also known as CYP3A4*1B) influences CYP3A4 expression as a result of altered nuclear protein binding affinity to the polymorphic element (Rodriguez-Antona and Ingelman-Sundberg, 2006).

The genotyping of CYP3A4 might help predict the treatment outcome of several drugs (Evans and Relling, 1999). However, because of the high cost of testing, the population frequencies of its various genotypes in a target population must be determined, to facilitate the design of an appropriate strategy for clinical application. Therefore, the aim of this study was to identify the genotypic and allelic frequencies of the CYP3A4 -392A>G (rs2740574) polymorphism in the São Luís population in Maranhão, Brazil.

\section{MATERIAL AND METHODS}

\section{Ethics statement}

This study was approved by the Committee of Ethics in Research of the University Hospital President Dutra of Universidade Federal do Maranhão on April 30, 2012 (CEP 007/2012). Informed consent was obtained from all enrolled patients prior to the study. 


\section{Samples}

In this study, 201 DNA samples were obtained from unrelated individuals from São Luís, Maranhão, Brazil, between April 2012 and April 2013 for polymorphism genotyping. The following exclusion criteria were applied for the selection of patients: no history of cancer, no alcohol or tobacco addiction, and no occupational diseases, immunodeficiencies, mental disorders, or neurological diseases. Additionally, an inability to answer the questionnaire was considered as an exclusion criterion.

The age of the included individuals varied from 18 to 91 years, with a mean of 61.8 years (standard deviation \pm 15.6 years); among these, $92(45.8 \%)$ were men and $109(54.2 \%)$ were women (Table 1).

Table 1. Gender, age, and CYP3A4 -392A>G polymorphism.

\begin{tabular}{|c|c|c|}
\hline \multirow[t]{2}{*}{ Features } & \multicolumn{2}{|c|}{ Frequencies } \\
\hline & No. & $(\%)$ \\
\hline \multicolumn{3}{|l|}{ Gender } \\
\hline Female & 109 & $(54.2)$ \\
\hline Male & 92 & $(45.8)$ \\
\hline \multicolumn{3}{|c|}{ Age, years (mean $\pm S D, 61.8 \pm 15.6$ years) } \\
\hline$\leq 40$ & 21 & $(10.5)$ \\
\hline $41-61$ & 61 & $(30.3)$ \\
\hline $61-80$ & 97 & $(48.3)$ \\
\hline$>80$ & 22 & $(10.9)$ \\
\hline \multicolumn{3}{|c|}{ Genotypic frequencies of CYP3A4 $-392 A>G$} \\
\hline AA & 151 & $(75.1)$ \\
\hline$A G$ & 44 & $(21.9)$ \\
\hline GG & 6 & $(3.0)$ \\
\hline \multicolumn{3}{|c|}{ Allelic frequencies of CYP3A4 $-392 A>G$} \\
\hline A & - & $(86.1)$ \\
\hline G & - & $(13.9)$ \\
\hline \multicolumn{3}{|c|}{ Hardy-Weinberg equilibrium } \\
\hline Chi square & \multicolumn{2}{|c|}{1.526} \\
\hline P value ${ }^{a}$ & \multicolumn{2}{|c|}{0.217} \\
\hline Total & 201 & $(100.0)$ \\
\hline
\end{tabular}

aEquilibrium was assumed when $\mathrm{P}>0.05$.

\section{Genotyping}

Genomic DNA was extracted from blood samples using the Biopur Kit mini spin plus (Biometrix Inc., San Francisco, CA, USA). The total concentration of isolated genomic DNA was determined using a NanoVue UVIVIS spectrophotometer (GE Healthcare, Fairfield, CT, USA). The CYP3A4*1B polymorphism was genotyped by polymerase chain reaction restriction fragment length polymorphism (PCR-RFLP). The following primers were used for the analysis: 5'-GGA CAG CCA TAG AGA CAA CTG CA-3' and 5'-CTT TCC TGC CCT GCA CAG-3', which produce a 334base pair (bp) fragment. The PCR was performed in a $25-\mu \mathrm{L}$ reaction mixture containing $50 \mathrm{ng}$ genomic DNA, 1 U HotStarTaq Plus Master Mix (containing the HotStarTaq Plus DNA Polymerase, PCR Buffer with $3 \mathrm{mM} \mathrm{MgCl}_{2}$, and $400 \mu \mathrm{M}$ dNTP each; Qiagen, Venlo, Netherlands), and 10 
pmol each primer. The reaction conditions were set as follows: initial denaturation at $94^{\circ} \mathrm{C}$ for 5 min, amplification for 40 cycles of denaturation at $94^{\circ} \mathrm{C}$ for $1 \mathrm{~min}$, annealing at $55^{\circ} \mathrm{C}$ for $1 \mathrm{~min}$, and extension at $72^{\circ} \mathrm{C}$ for $1 \mathrm{~min}$, and a final extension at $72^{\circ} \mathrm{C}$ for $10 \mathrm{~min}$. The PCR products were digested overnight with a restriction endonuclease Pstl (Jena Bioscience, Jena, Germany), following the manufacturer recommendations. The restriction fragments were resolved on a $2 \%$ agarose gel. The CYP3A4*1B allele was characterized by four distinctive fragments of 199, 81, 33, and 21-bp, whereas the CYP3A4 wild-type allele was identified by three fragments 220,81 , and 33-bp long.

\section{Statistical analysis}

Statistical data analysis was done using SPSS Statistics 20.0 (IBM, Armonk, NY, USA). The genotypic frequencies were tested for conformance with the Hardy-Weinberg Equilibrium (HWE). The chi square test was also used to assess deviations of allelic frequencies from the HWE.

\section{RESULTS}

The AA (wild type), AG, and GG genotypes of the CYP3A4 -392A >G polymorphism was observed in $151(75.1 \%), 44$ (21.9\%), and 6 (3.0\%) of the test subjects, respectively. The allele frequencies of the $-392 \mathrm{~A}$ and $-392 \mathrm{G}$ alleles were $86.1 \%$ and $13.9 \%$, respectively. The genotype frequencies were in line with the HWE $(P>0.05)$. As show in Table 1, the homozygote of the $-392 \mathrm{~A}$ allele of $C Y P 3 A 4^{*} B$ was predominant.

\section{DISCUSSION}

Inter-individual variability in drug metabolism, which can result in poor drug response, adverse drug reactions, or unfavorable drug-drug interactions, is a preeminent concern in drug development and treatment. Pharmacogenetic studies have shown that polymorphisms of drugmetabolizing enzymes, transporters, and receptors contribute to variable drug response (Waxman et al., 1988).

CYP3A4 is responsible for the metabolism of over $50 \%$ of all clinically used drugs, including commonly used antidepressants, antibiotics, antihypertensives, steroids, and immunosuppressants (Von Hentig and Lötsch, 2009). Thus, polymorphisms in the CYP family may have a majority impact on the fate of these drugs, and other therapeutic drugs whose metabolism they regulate (Evans and Relling, 1999).

CYP3A4 -392A>G has been previously analyzed in a Brazilian population. Jeovanio-Silva et al. (2012), in a study of a sample population in the State of Rio de Janeiro in Brazil, observed that $59.5 \%$ of 106 test subjects expressed a homozygous genotype (45.3\% -392AA and $14.2 \%$ $-392 \mathrm{GG}$ ), while $40.5 \%$ displayed a heterozygote genotype; in this study, the $-392 \mathrm{G}$ and $-392 \mathrm{~A}$ alleles were observed in $34 \%$ and $66 \%$ of the Brazilian subjects, respectively.

Another related study of the genotype frequency of CYP3A4 in Rio Grande do Sul (Brazil) revealed that $94.8 \%$ of the sample population displayed the -392AA genotype and $5.2 \%$ showed the -392AG genotype; however, the -392GG genotype was not observed in these individuals. Consequently, the allelic frequency of $-392 \mathrm{G}$ was only $2.6 \%$ (Fiegenbaum et al., 2005). These 
results were very similar to those observed in a Caucasian sample population, wherein $91.9 \%$ of the population displayed the -392AA genotype; $7.9 \%$ and $0.1 \%$ of the total sample population were heterozygous and homozygous $-392 \mathrm{G}$ carriers, respectively (Becker et al., 2010).

In this study, we observed that $86.1 \%$ and $13.9 \%$ of the population expressed the $-392 \mathrm{~A}$ and $-392 \mathrm{G}$ alleles; the genotypic distribution of -392AA, -392AG, and -392GG was $75.1 \%, 21.9 \%$, and $3.0 \%$, respectively. The allelic and genotypic frequencies of the CYP3A4 SNP observed in our study was similar to those observed in other studies in Brazilian individuals (Cavalli et al., 2008), while differing from the results of studies in other populations (Fiegenbaum et al., 2005; Becker et al., 2010; Jeovanio-Silva et al., 2012).

Brazil presents a large miscegenation of Native American Indians, European Caucasians, and African blacks originating from various countries. Because of the geographical enormity, topographic diversity, and colonization history of Brazil, different regions display a singular prevalence of ancestry that is reflected in the population subtypes (Alves-Silva et al., 2000). This justifies the large variation in the results of studies in Brazilian population genetics, underscoring the need for studies focusing on different regions of Brazil and different population subtypes.

In conclusion, the variant frequency of CYP $3 A 4$ polymorphisms among different ethnic groups may significantly contribute to the drug efficacy and toxicity. Based on these results, it is necessary to specifically examine the genetic frequencies of the CYP3A4-392A $>G$ polymorphism in different regions in Brazil, in order to promote greater understanding of their role in pharmacological response.

\section{Conflicts of interest}

The authors declare no conflict of interest.

\section{ACKNOWLEDGMENTS}

The authors would like to thank the DNA Biobank of Maranhão (BTMA) for the technical support and CAPES for the Masters' scholarship.

\section{REFERENCES}

Alves-Silva J, da Silva Santos M, Guimarães PE, Ferreira AC, et al. (2000). The ancestry of Brazilian mtDNA lineages. Am. J. Hum. Genet. 67: 444-461. http://dx.doi.org/10.1086/303004

Becker ML, Visser LE, van Schaik RH, Hofman A, et al. (2010). Influence of genetic variation in CYP3A4 and ABCB1 on dose decrease or switching during simvastatin and atorvastatin therapy. Pharmacoepidemiol. Drug Saf. 19: 75-81. http://dx.doi.org/10.1002/pds.1866

Cavalli SA, Rebecchi IMM, Matsumoto LO, Basques HH, et al. (2008). Lowering cholesterol response to atorvastatin is not influenced by CYP3A4*1B. Bio Farma 3: 29-35.

Deenen MJ, Cats A, Beijnen JH and Schellens JH (2011). Part 2: pharmacogenetic variability in drug transport and phase I anticancer drug metabolism. Oncologist 16: 820-834. http://dx.doi.org/10.1634/theoncologist.2010-0259

Evans WE and Relling MV (1999). Pharmacogenomics: translating functional genomics into rational therapeutics. Science 286: 487-491. http://dx.doi.org/10.1126/science.286.5439.487

Fiegenbaum M, da Silveira FR, Van der Sand CR, Van der Sand LC, et al. (2005). The role of common variants of ABCB1, CYP3A4, and CYP3A5 genes in lipid-lowering efficacy and safety of simvastatin treatment. Clin. Pharmacol. Ther. 78: 551-558. http://dx.doi.org/10.1016/j.clpt.2005.08.003

Guengerich FP (1999). Cytochrome P-450 3A4: regulation and role in drug metabolism. Annu. Rev. Pharmacol. Toxicol. 39: 1-17. http://dx.doi.org/10.1146/annurev.pharmtox.39.1.1 
Jeovanio-Silva AL, Monteiro TP, El-Jaick KB, do Brasil PE, et al. (2012). Unique CYP3A4 genetic variant in Brazilian tuberculosis patients with/without HIV. Mol. Med. Rep. 5: 153-161.

Ozdemir V, Kalow W, Tang BK, Paterson AD, et al. (2000). Evaluation of the genetic component of variability in CYP3A4 activity: a repeated drug administration method. Pharmacogenetics 10: 373-388. http://dx.doi.org/10.1097/00008571-200007000-00001

Rodriguez-Antona C and Ingelman-Sundberg M (2006). Cytochrome P450 pharmacogenetics and cancer. Oncogene 25: 1679-1691. http://dx.doi.org/10.1038/sj.onc.1209377

Rodríguez-Antona C, Sayi JG, Gustafsson LL, Bertilsson L, et al. (2005). Phenotype-genotype variability in the human CYP3A locus as assessed by the probe drug quinine and analyses of variant CYP3A4 alleles. Biochem. Biophys. Res. Commun. 338: 299-305. http://dx.doi.org/10.1016/j.bbrc.2005.09.020

Shimada T, Yamazaki H, Mimura M, Inui Y, et al. (1994). Interindividual variations in human liver cytochrome P-450 enzymes involved in the oxidation of drugs, carcinogens and toxic chemicals: studies with liver microsomes of 30 Japanese and 30 Caucasians. J. Pharmacol. Exp. Ther. 270: 414-423.

Von Hentig N and Lötsch J (2009). Cytochrome P450 3A inhibition by atazanavir and ritonavir, but not demography or drug formulation, influences saquinavir population pharmacokinetics in human immunodeficiency virus type 1-infected adults. Antimicrob. Agents Chemother. 53: 3524-3527. http://dx.doi.org/10.1128/AAC.00025-09

Waxman DJ, Attisano C, Guengerich FP and Lapenson DP (1988). Human liver microsomal steroid metabolism: identification of the major microsomal steroid hormone 6 beta-hydroxylase cytochrome P-450 enzyme. Arch. Biochem. Biophys. 263: 424-436. http://dx.doi.org/10.1016/0003-9861(88)90655-8 